\title{
Perception of Nursing Teaching Staff on the Use of Objective Structured Clinical Examinations (OSCE): Assessment Method
}

\author{
Naglaa Saad Abed El-aty ${ }^{1}$, Abeer Mohamed Abdelkader Othman ${ }^{2}$ and Aml \\ Sayed Ali Abd Elrahem ${ }^{3}$ \\ 1. Lecturer of community health nursing, Faculty of Nursing, Assiut University, Assiut \\ 2. Lecturer of nursing education, Faculty of Nursing, Minia University, Minia \\ 3. Lecturer Pediatric nursing, Faculty of Nursing, Minia University, Minia
}

\begin{abstract}
Background: Assessment of clinical competence is an important issue in nursing education and the utilization of objective structured clinical evaluation for that purpose was considered to be very important so perception of nursing teaching staff is important for developing the in exam methodology and organization. The aim of the study: to describe the perceptions of nursing teaching staff regarding Objective Structured Clinical Examination (OSCE ) Design: A descriptive cross - sectional study was used in this study. Setting: study was conducted in Faculty of Nursing, Assiut University. Sample: A total number of 133 convenient samples of nursing teaching staff were included in the study Tools: A self-administered questionnaire of perception about OSCE. The questionnaire comprise of six parts, (Likert scale) regarding the nursing staffs' perception of OSCE question/ station, exam organization, exam atmosphere, student performance, advantages of OSCE and disadvantages of OSCE. Results: The mean age of studied sample was 36.39 year. About two third of nursing teaching staff agreed that OSCE scores (marks) provided true measure of essential clinical skills needed by student in different disciplines, $75.2 \%$ of nursing staff members agreed that exam was fair while $45.9 \%$ of studied sample agreed that exam highlighted areas of students' weakness. Most of sample agreed that OSCE exam was well organized, while only (51.1\%) of sample agreed that more time was needed at each station. $47.4 \%$ agreed that the environment motivated students to learn, $72.9 \%$ agreed that atmosphere was calm, while $23.3 \%$ and $27.1 \%$ agreed that exam was intimidating (frightening) and exam was very stressful respectively. Moderate correlation and significant between nursing staff members perception of students performance and their age, $r=0.196$ and $p=0.024$. There are significant differences between disadvantages of OSCE their occupation $p=0.003$. Also positive perception of nursing teaching staff regarding OSCE exam was positive (90.1\%). Conclusion: positive for all the domains in the questionnaire and total perception of nursing staff members regarding OSCE exam was very positively. The majority of nursing staff members reported that preparation of stations requires more resources and continuous process. Recommendations: Students should also be trained for this type of exam; the best way is to start examining them using this strategy (OSCE) earlier and more is staff needed for this type of exams and more training should be done to staff through journal club. Keywords: objective structured clinical examinations, nursing teaching staff, perception, nursing education
\end{abstract}

\section{Introduction}

One of the essential components of learning and educational program is evaluation or examination. There are various methods for evaluating clinical skills among which objective structured clinical examination (OSCE) has been recognized as the most reliable method for evaluation of the clinical skills.( Hosseini et al; 2011) During recent years, Objective structured clinical examination (OSCE) has been used in nursing education and other health care professions. It has currently become a popular tool for assessing clinical competence in nursing (Walsh et al; 2009) and it is now emerged in other disciplines including, pharmacy, and dentistry to test clinical skill performance. (Eswi et al.2013).

The Objective Structured Clinical Examination (OSCE) is considered as a useful method of teaching because it is a safe practice to help students gain more confidence when confronted by technical instruments present in the hospital environment (Mater et al; 2014). It is defined as "the method of choice for evaluation of learner's clinical competence (Al Saegh, 2015). OSCE demonstrate particular advantages over traditional forms of testing such as multiple choice tests, in assessing communication and interpersonal skills, professional judgment and moral/ethical reasoning (Mahmoud and Mostafa, 2011).

In addition to assessing the competence and performance of the examinee, OSCE has many advantages over traditional methods of evaluation such as conventional bedside long and short case examinations. As an evaluation tool, it eliminates the luck of the draw, reduces variations in marking standards from examiner to examiner (Eswi et al.2013). It has demonstrated reliability and validity for assessing clinical performance, but its construction and running needs effort, time and some expertise (Idris et al; 2014). 
OSCE is as examinations where students demonstrate their competence under a variety of simulated conditions. The competencies include patient care, medical knowledge, interpersonal and communication skills, professionalism, practice-based learning and improvement throughout the course curriculum (Baid, 2011). Also OSCE includes multiple clinical situations (termed stations) involving case-based scenarios and interaction with trained standardized patients, structured objective checklists; written summary of clinical history, physical examination findings, therapeutic management and performance review (Casey et al;2009).

During the OSCE, students rotate around a circuit of stations on a timed based station. At the ring of a bell, each student enters the station assess a different clinical competency such as history taking, interpretation or more clinical task or solving a problem (Ahmed, et al;2009). All students get examined on predetermined criteria on same or similar clinical scenario or tasks with marks written down against those criteria thus enabling recall, teaching audit and determination of standards. (Zayyan 2011). The introduction of a larger number of short stations (5 minutes each) was also proposed to ensure validity and reliability of this assessment method.( Idris ,et al; 2014)

The assessment of knowledge and skills plays an important part in student nurses' progression though pre-registration programs because they need to demonstrate competency and confidence in the performance of clinical skills. The pyramid of competence (Miller, 1990) which outlines four levels at which a learner can be assessed: knows, knows how, shows how and does and is a framework that identifies the stages of skills students should achieve (Fig 1). In progressing up the pyramid to "shows how", students demonstrate their knowledge and understanding by performing in a simulated setting such as an OSCE.

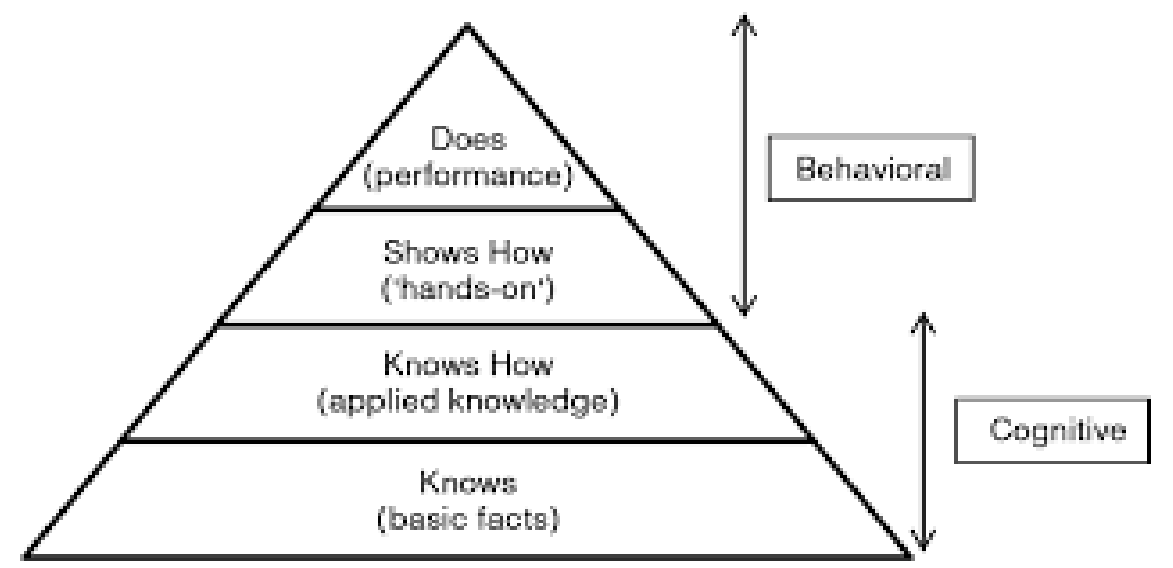

Figure(1). The Development of Clinical Skills / Competence / Performance (adapted from Miller

1990) Firstly, OSCEs may be used as a summative or formative assessment and on their own or with another form of assessment. Summative OSCEs are frequently used at the end of courses or programs, or on completion of a module to test students against set objectives and learning outcomes. Where they are used as a formative assessment, the feedback provided helps students to progress. Formative OSCEs also help to prepare students for placements, encourage them to engage with their learning and help them to achieve their learning outcomes (Liddle, 2014)

Secondly, because each student is required to demonstrate specific behaviors in a simulated work environment, strict control over the clinical context is possible, while at the same time, reflecting real-life professional tasks ((Bartfay et al 2004) .

Teachers' perception on exams is a very important aspect for improvements in the quality and credibility of exams. Clinical exams have always been at the center of attraction in medical schools, however only until recently has the OSCE gained popularity as the ultimate solution for subjectivity in clinical exams. A series of workshops were carried out in order to train teachers for OSCE preparation. Teachers' perception of the exam itself and organization was very important as a baseline for improvements in future exams (Sara et al; 2012)

\section{Significance of study}

The nursing occupation is characterized by the fact that a significant amount of time is spent on competency-related activities. The assessment of clinical competence is therefore an important issue in nursing education and the utilization of objective structured clinical evaluation for that purpose was considered to be very important in this study. 


\section{Research Question}

- Are there differences in perceptions regarding Objective Structured Clinical Examination (OSCE) among nursing teaching staff?

\subsection{Research design}

\section{Subjects and methods}

A descriptive cross - sectional study design was used in the this study

4.2 Setting

The study was conducted in Faculty of Nursing, Assiut University

\subsection{Sample:}

The total studied sample was 133 nursing staff members were selected through a convenient sample technique.

\begin{tabular}{|l|c|}
\hline Instructor & 29 \\
\hline Assistant Lecturer & 20 \\
\hline Lecturer & 52 \\
\hline Assistant Professor & 23 \\
\hline Professor & 9 \\
\hline
\end{tabular}

\subsection{Exclusion criteria}

New instructors who had years of experience less than two years.

\subsection{Data collection Tools}

The questionnaire was designed and filled in by the faculty members who involved in OSCE. The used questionnaire comprising of six parts, (Likert scale) consisting of 55 items out of which 20 items were regarding the nursing staffs' perception of OSCE question/ station, 8 regarding the organization, six items for exam atmosphere, six items for student performance, nine items for Advantages of OSCE and the last six items regarding Disadvantages of OSCE. The questionnaire was distributed to staff members of the faculty from June 2016 to December 2016 and returned for assessment of their responses. The results were graded on the Likert scale, graded from 0-2; 2 for agree, 1 for neutral and zero for disagree. The score was reversed for negative statements. The total score was calculated by summing up scores and converting them into a percent score. Perception considered positive if the score $60 \%$ and more and negative perception if the score was less than $60 \%$ (Nady et al; 2014) Validity of tool was checked and revised by panel of five experts in nursing field , Faculty of Nursing Assiut University, whom reviewed the instrument for clarity, relevance, comprehensiveness, and applicability.

Reliability of tool was assessed using alpha - Cronbach test to test the internal consistency r 0.865

A pilot study was carried on $(10 \%)$ of the sample. It was conducted to assess clarity of the questions, the need for any rewording and/or rephrasing and time needed to fulfill the questionnaire. As the result of the pilot study, there weren't modifications in the questionnaire. Data of the pilot study were included in the study sample.

\subsection{Ethical considerations:}

- The study protocol was approved by the ethical committee of faculty of nursing, Assiut University.

- The researchers assured voluntary participation and confidentiality of each member who agrees to participate in this study.

\subsection{Data management and statistical Analysis:}

Data were entered, cleaned and recoded (if needed) using the Statistical Package for Social Science (SPSS Inc., Chicago, IL, USA) version 20. Data analysis was done in the form of univariate analysis: descriptive statistics (frequency \& percent for qualitative data, mean \pm SD for quantitative data). Bivariate analysis: cross tabulation. Chi-square test (X2) was used to test the difference between the proportions of qualitative data. Statistical significance level was considered when $\mathrm{p}$-value $<0.05$ for all statistical tests.

\section{Results}

Table (1): Distribution of nursing staff members regarding to their personal characteristics

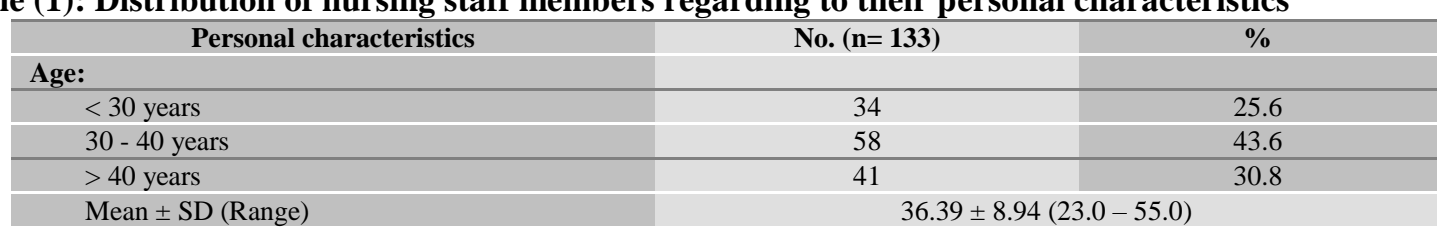




\begin{tabular}{|c|c|c|}
\hline \multicolumn{3}{|l|}{ Occupation: } \\
\hline Instructor & 29 & 21.8 \\
\hline Assistant Lecturer & 20 & 15.0 \\
\hline Lecturer & 52 & 39.1 \\
\hline Assistant Professor & 23 & 17.3 \\
\hline Professor & 9 & 6.8 \\
\hline \multicolumn{3}{|l|}{ Department: } \\
\hline Adult nursing & 30 & 22.6 \\
\hline $\mathrm{CHN}$ & 18 & 13.5 \\
\hline Critical & 11 & 8.3 \\
\hline Geriatric & 9 & 6.8 \\
\hline Nursing administration & 16 & 12.0 \\
\hline Obstetric & 14 & 10.5 \\
\hline Pediatric & 20 & 15.0 \\
\hline Psychiatric & 15 & 11.3 \\
\hline
\end{tabular}

Table (2): Nursing staffs members' perception of OSCE question/ station

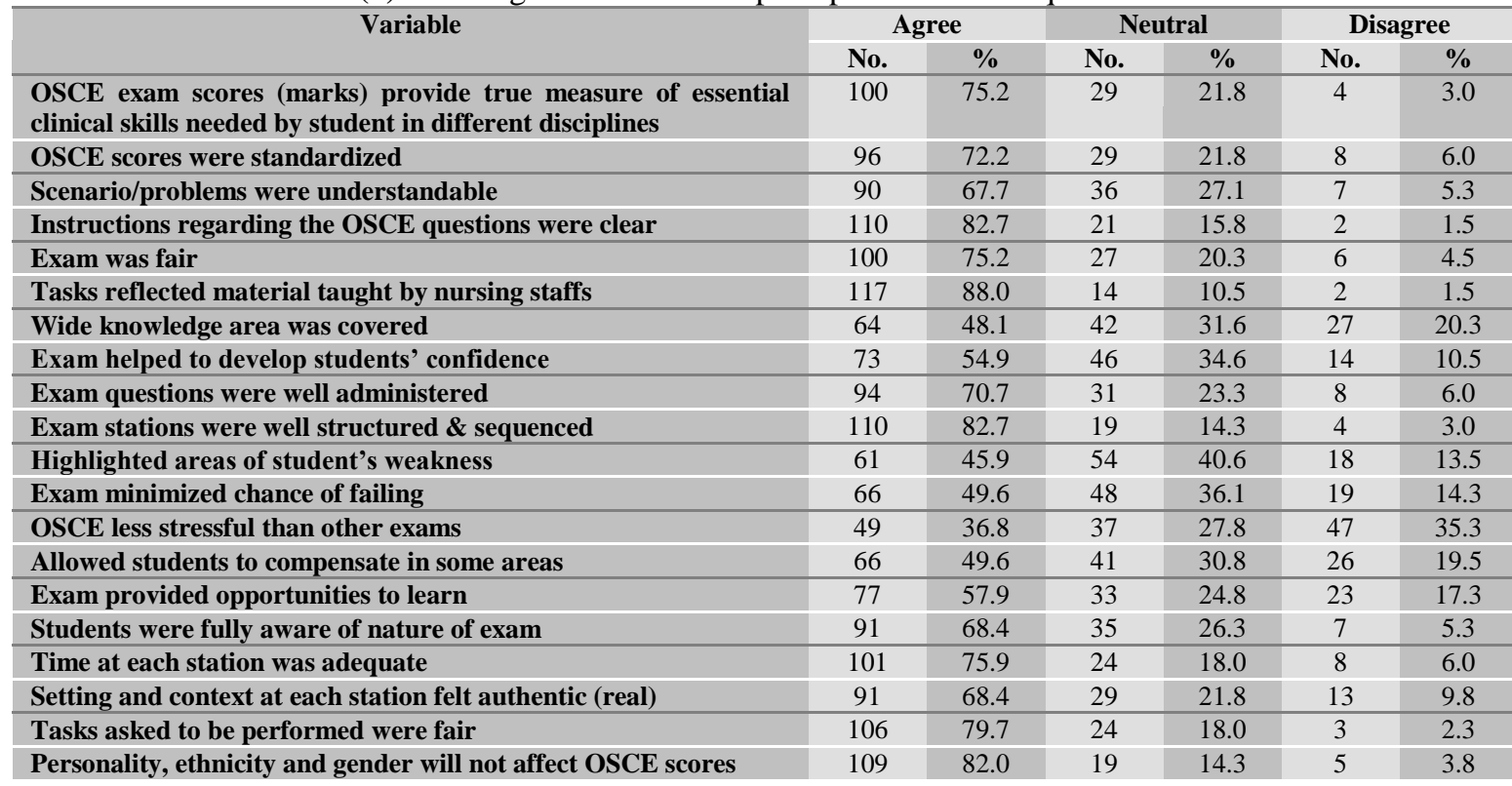

Table (3): Nursing staff members' perception regarding OSCE organization

\begin{tabular}{|c|c|c|c|c|c|c|}
\hline \multirow[t]{2}{*}{ Variable } & \multicolumn{2}{|c|}{ Agree } & \multicolumn{2}{|c|}{ Neutral } & \multicolumn{2}{|c|}{ Disagree } \\
\hline & No. & $\%$ & No. & $\%$ & No. & $\%$ \\
\hline OSCE exam was well organized & 121 & 91.0 & 12 & 9.0 & 0 & 0.0 \\
\hline Sequence of stations was logical and appropriate & 114 & 85.7 & 19 & 14.3 & 0 & 0.0 \\
\hline Instructions for moving about stations were clear & 111 & 83.5 & 20 & 15.0 & 2 & 1.5 \\
\hline Staff directed students to stations smoothly and efficiently & 109 & 82.0 & 21 & 15.8 & 3 & 2.3 \\
\hline Staff was helpful & 112 & 84.2 & 15 & 11.3 & 6 & 4.5 \\
\hline Needed more time at stations & 68 & 51.1 & 26 & 19.5 & 39 & 29.3 \\
\hline More staff is needed for supervision & 89 & 66.9 & 22 & 16.5 & 22 & 16.5 \\
\hline More training of staff is required & 81 & 60.9 & 17 & 12.8 & 35 & 26.3 \\
\hline
\end{tabular}

Table (4): Nursing staff members perception about OSCE exam atmosphere

\begin{tabular}{|c|c|c|c|c|c|c|}
\hline \multirow[t]{2}{*}{ Variable } & \multicolumn{2}{|c|}{ Agree } & \multicolumn{2}{|c|}{ Neutral } & \multicolumn{2}{|c|}{ Disagree } \\
\hline & No. & $\%$ & No. & $\%$ & No. & $\%$ \\
\hline The atmosphere motivated students to learn & 63 & 47.4 & 43 & 32.3 & 27 & 20.3 \\
\hline Atmosphere was calm so as to allow students to concentrate & 97 & 72.9 & 30 & 22.6 & 6 & 4.5 \\
\hline Exam was intimidating (frightening) & 31 & 23.3 & 42 & 31.6 & 60 & 45.1 \\
\hline Exam was very stressful & 36 & 27.1 & 38 & 28.6 & 59 & 44.4 \\
\hline I found the experience unsatisfactory & 29 & 21.8 & 40 & 30.1 & 64 & 48.1 \\
\hline
\end{tabular}


Table (5): Nursing staff members perception regarding student performance

\begin{tabular}{|c|c|c|c|c|c|c|}
\hline \multirow[t]{2}{*}{ Variable } & \multicolumn{2}{|c|}{ Agree } & \multicolumn{2}{|c|}{ Neutral } & \multicolumn{2}{|c|}{ Disagree } \\
\hline & No. & $\%$ & No. & $\%$ & No. & $\%$ \\
\hline The students were well prepared for the OSCE & 96 & 72.2 & 26 & 19.5 & 11 & 8.3 \\
\hline Students asked logical questions regarding exam & 112 & 84.2 & 20 & 15.0 & 1 & 0.8 \\
\hline Students got agitated during exam & 41 & 30.8 & 43 & 32.3 & 49 & 36.8 \\
\hline Students were frightened by the exam & 35 & 26.3 & 47 & 35.3 & 51 & 38.3 \\
\hline
\end{tabular}

Table (6): Advantages of OSCE as expressed by nursing staff members

\begin{tabular}{|c|c|c|c|c|c|c|}
\hline \multirow[t]{2}{*}{ Variable } & \multicolumn{2}{|c|}{ Agree } & \multicolumn{2}{|c|}{ Neutral } & \multicolumn{2}{|c|}{ Disagree } \\
\hline & No. & $\%$ & No. & $\%$ & No. & $\%$ \\
\hline $\begin{array}{l}\text { Students will learn at least some skills required for future } \\
\text { practice }\end{array}$ & 106 & 79.7 & 13 & 9.8 & 14 & 10.5 \\
\hline It is highly accepted by students and faculty & 91 & 68.4 & 36 & 27.1 & 6 & 4.5 \\
\hline Improves clinical skills \& knowledge of students & 73 & 54.9 & 53 & 39.8 & 7 & 5.3 \\
\hline More conceptual learning & 88 & 66.2 & 42 & 31.6 & 3 & 2.3 \\
\hline $\begin{array}{l}\text { Attitude of examiners is better } \\
\text { as compared to traditional } \\
\text { clinical examination }\end{array}$ & 104 & 78.2 & 26 & 19.5 & 3 & 2.3 \\
\hline $\begin{array}{l}\text { Feedback given by examiners } \\
\text { was very helpful }\end{array}$ & 101 & 75.9 & 23 & 17.3 & 9 & 6.8 \\
\hline
\end{tabular}

Table (7): Disadvantages of OSCE as expressed by nursing staff members

\begin{tabular}{|c|c|c|c|c|c|c|}
\hline \multirow[t]{2}{*}{ Variable } & \multicolumn{2}{|c|}{ Agree } & \multicolumn{2}{|c|}{ Neutral } & \multicolumn{2}{|c|}{ Disagree } \\
\hline & No. & $\%$ & No. & $\%$ & No. & $\%$ \\
\hline $\begin{array}{l}\text { Only specific questions are to be asked as in checklists or } \\
\text { model answers }\end{array}$ & 102 & 76.7 & 18 & 13.5 & 13 & 9.8 \\
\hline $\begin{array}{l}\text { Preparation of stations requires more resources and } \\
\text { continuous process }\end{array}$ & 119 & 89.5 & 8 & 6.0 & 6 & 4.5 \\
\hline Little difficult to manage time at stations & 83 & 62.4 & 28 & 21.1 & 22 & 16.5 \\
\hline No direct interaction with examiners & 56 & 42.1 & 12 & 9.0 & 65 & 48.9 \\
\hline
\end{tabular}

Table (8): Total score perception of nursing staff members regarding OSCE

\begin{tabular}{|c|c|c|}
\hline Variable & No. $(n=133)$ & $\%$ \\
\hline \multicolumn{3}{|c|}{ Nursing staffs' perception of OSCE question/ station: } \\
\hline Negative $(<60 \%)$ & 14 & 10.5 \\
\hline Positive $(\geq 60 \%)$ & 119 & 89.5 \\
\hline \multicolumn{3}{|c|}{ Nursing staff perception of organization: } \\
\hline Negative $(<60 \%)$ & 3 & 2.3 \\
\hline Positive $(\geq 60 \%)$ & 130 & 97.7 \\
\hline \multicolumn{3}{|c|}{ Nursing staff perception of exam atmosphere: } \\
\hline Negative $(<60 \%)$ & 48 & 36.1 \\
\hline Positive $(\geq 60 \%)$ & 85 & 63.9 \\
\hline \multicolumn{3}{|c|}{ Nursing staff perception of student performance: } \\
\hline Negative $(<60 \%)$ & 51 & 38.3 \\
\hline Positive $(\geq 60 \%)$ & 82 & 61.7 \\
\hline \multicolumn{3}{|c|}{ Advantages of OSCE as expressed by nursing staff: } \\
\hline Negative $(<60 \%)$ & 9 & 6.8 \\
\hline Positive $(\geq 60 \%)$ & 124 & 93.2 \\
\hline \multicolumn{3}{|c|}{ Disadvantages of OSCE as expressed by nursing staff: } \\
\hline Negative $(<60 \%)$ & 42 & 31.6 \\
\hline Positive $(\geq 60 \%)$ & 91 & 68.4 \\
\hline \multicolumn{3}{|l|}{ Total score of perception: } \\
\hline Negative $(<60 \%)$ & 12 & 9.0 \\
\hline Positive $(\geq 60 \%)$ & 121 & 91.0 \\
\hline
\end{tabular}


Fig (1): Total score of perception

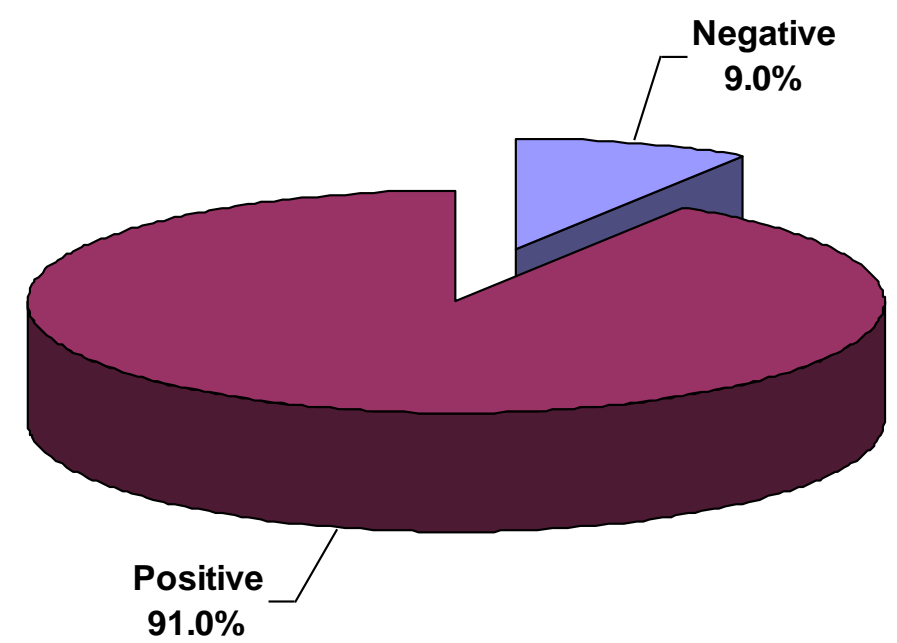

Table (9): correlation coefficient values for the relationship between OSCE attributes as perceived by nursing staff members

\begin{tabular}{|c|c|c|c|c|c|c|c|c|}
\hline $\begin{array}{l}\text { OSCE questionnaire } \\
\text { factors }\end{array}$ & & $\begin{array}{c}\text { Nursing } \\
\text { staffs' } \\
\text { perception } \\
\text { of OSCE } \\
\text { question/stati } \\
\text { on }\end{array}$ & $\begin{array}{l}\text { Nursing staff } \\
\text { perception of } \\
\text { organization }\end{array}$ & $\begin{array}{c}\text { Nursing staff } \\
\text { perception of } \\
\text { exam } \\
\text { atmosphere }\end{array}$ & $\begin{array}{l}\text { Nursing staff } \\
\text { perception } \\
\text { of student } \\
\text { performance }\end{array}$ & $\begin{array}{c}\text { Advantages } \\
\text { of } \\
\text { OSCE as } \\
\text { expressed } \\
\text { by nursing } \\
\text { staff }\end{array}$ & $\begin{array}{l}\text { Disadvantages } \\
\text { of OSCE as } \\
\text { expressed by } \\
\text { nursing staff }\end{array}$ & $\begin{array}{c}\text { Total } \\
\text { score } \\
\text { of } \\
\text { percept } \\
\text { on }\end{array}$ \\
\hline \multirow{2}{*}{$\begin{array}{l}\text { Nursing staffs' } \\
\text { perception of OSCE } \\
\text { question/ station } \\
\end{array}$} & r-value & & & & & & & \\
\hline & P-value & & & & & & & \\
\hline \multirow{2}{*}{$\begin{array}{l}\text { Nursing staff perception } \\
\text { of organization }\end{array}$} & r-value & 0.348 & & & & & & \\
\hline & P-value & 0.000* & & & & & & \\
\hline \multirow{2}{*}{$\begin{array}{l}\text { Nursing staff perception } \\
\text { of exam atmosphere }\end{array}$} & r-value & 0.409 & 0.024 & & & & & \\
\hline & P-value & 0.000* & 0.783 & & & & & \\
\hline \multirow{2}{*}{$\begin{array}{l}\text { Nursing staff perception } \\
\text { of student performance }\end{array}$} & r-value & 0.188 & -0.099 & 0.516 & & & & \\
\hline & P-value & 0.031* & 0.255 & 0.000* & & & & \\
\hline \multirow{2}{*}{$\begin{array}{l}\text { Advantages of OSCE } \\
\text { as expressed by nursing } \\
\text { staff }\end{array}$} & r-value & 0.477 & 0.178 & 0.475 & 0.273 & & & \\
\hline & P-value & $0.000 *$ & $0.040 *$ & $0.000 *$ & 0.001* & & & \\
\hline \multirow{2}{*}{$\begin{array}{l}\text { Disadvantages of OSCE } \\
\text { as expressed by nursing } \\
\text { staff }\end{array}$} & r-value & 0.315 & 0.090 & $\begin{array}{l}0.270 \\
\end{array}$ & 0.265 & 0.202 & & \\
\hline & P-value & 0.000* & 0.305 & 0.002* & 0.002* & 0.020* & & \\
\hline \multirow{2}{*}{$\begin{array}{l}\text { Total score of } \\
\text { perception }\end{array}$} & r-value & 0.839 & 0.404 & 0.670 & 0.467 & 0.664 & 0.478 & \\
\hline & P-value & 0.000* & 0.000* & 0.000* & 0.000* & $0.000 *$ & 0.000* & \\
\hline
\end{tabular}

*. Correlation is significant at the 0.05 level (2-tailed).

Table (10): Relation between score of perception and occupation of nursing staff members regarding OSCE

\begin{tabular}{|c|c|c|c|c|c|c|}
\hline \multirow[t]{3}{*}{ Variable } & \multicolumn{5}{|c|}{ Occupation } & \multirow[t]{3}{*}{ P-value } \\
\hline & Instructor & $\begin{array}{l}\text { Assistant } \\
\text { Lecturer }\end{array}$ & Lecturer & $\begin{array}{l}\text { Assistant } \\
\text { Professor }\end{array}$ & Professor & \\
\hline & Mean \pm SD & Mean \pm SD & Mean \pm SD & Mean \pm SD & Mean \pm SD & \\
\hline $\begin{array}{l}\text { Nursing staffs' perception } \\
\text { of OSCE question/ station }\end{array}$ & $33.14 \pm 6.83$ & $33.50 \pm 6.86$ & $33.31 \pm 5.56$ & $31.96 \pm 7.00$ & $34.00 \pm 4.95$ & 0.896 \\
\hline $\begin{array}{l}\text { Nursing staff perception } \\
\text { of organization }\end{array}$ & $13.66 \pm 1.72$ & $12.40 \pm 2.33$ & $13.67 \pm 2.06$ & $12.52 \pm 2.27$ & $13.22 \pm 2.28$ & 0.059 \\
\hline
\end{tabular}


Perception of Nursing Teaching Staff on the Use of Objective Structured Clinical Examinations ..

\begin{tabular}{|c|c|c|c|c|c|c|}
\hline $\begin{array}{l}\text { Nursing staff perception } \\
\text { of exam atmosphere }\end{array}$ & $8.00 \pm 1.95$ & $8.85 \pm 2.37$ & $8.02 \pm 2.43$ & $8.39 \pm 3.10$ & $9.11 \pm 2.03$ & 0.531 \\
\hline $\begin{array}{l}\text { Nursing staff perception } \\
\text { of student performance }\end{array}$ & $7.93 \pm 2.17$ & $7.95 \pm 2.14$ & $8.15 \pm 2.00$ & $7.65 \pm 2.29$ & $10.22 \pm 2.39$ & $0.043 *$ \\
\hline $\begin{array}{l}\text { Advantages of OSCE as } \\
\text { expressed by nursing staff }\end{array}$ & $14.83 \pm 2.58$ & $15.50 \pm 2.87$ & $14.75 \pm 2.37$ & $13.83 \pm 4.40$ & $16.33 \pm 1.80$ & 0.188 \\
\hline $\begin{array}{l}\text { Disadvantages of OSCE as } \\
\text { expressed by nursing staff }\end{array}$ & $7.38 \pm 1.59$ & $8.75 \pm 2.10$ & $8.35 \pm 1.77$ & $7.26 \pm 1.81$ & $9.22 \pm 1.20$ & $0.003 *$ \\
\hline Total score of perception & $84.93 \pm 12.91$ & $86.95 \pm 12.31$ & $86.25 \pm 10.58$ & $81.61 \pm 16.99$ & $92.11 \pm 6.79$ & 0.269 \\
\hline
\end{tabular}

Figure (2): Correlation between nursing staff members' perception of students performance and their age

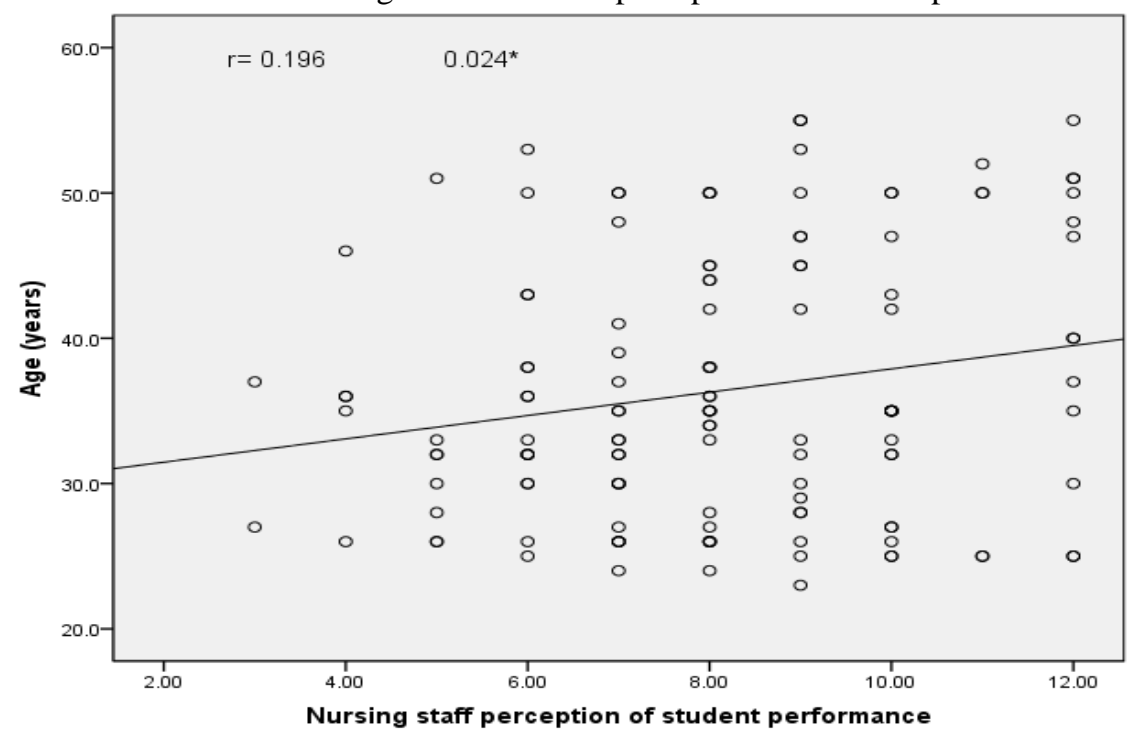

Figure (3): Correlation between nursing staff members' perception of disadvantages and their age

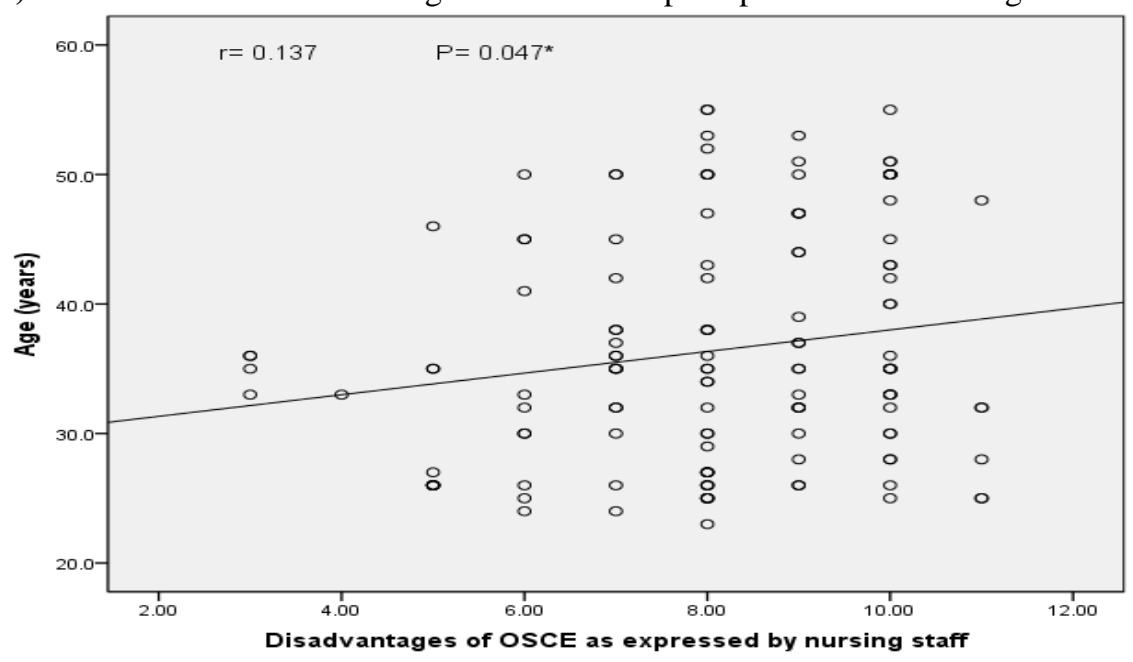

The present study included 133 nursing staff members, $43.6 \%$ of them aged between $30-40$ years, with mean age $36.39 \pm 8.94(23.0-55.0), 39.1 \%$ of them were Lecturers and $22.6 \%$ of them were working at adult nursing department.

The results of the present study donated that $75.2 \%$ of nursing staff members agreed OSCE scores (marks) provided true measure of essential clinical skills needed by student in different disciplines. $75.2 \%$ of nursing staff members agreed that exam was fair and more than four fifth $(88 \%)$ of nursing staff members agreed that tasks reflected material taught by nursing staffs. $45.9 \%$ of studied sample agreed that exam highlighted areas of students' weakness, while $40.6 \%$ and $13.5 \%$ of them were neutral and disagreed respectively. More than on third $(36.8 \%)$ of studied sample agreed that OSCE less is stressful than other exams.

Concerning to nursing staff perception regarding OSCE organization, the present study revealed that the majority $(91.0 \%)$ of nursing staff members agreed that OSCE exam was well organized. More than four fifth

DOI: $10.9790 / 1959-0602062736 \quad$ www.iosrjournals.org $33 \mid$ Page


$(85.7 \%)$ of nursing staff members agreed that agreed that Sequence of stations was logical and appropriate. Also the present study showed that more than one half $(51.1 \%)$ of nursing staff members agreed that more time was needed at each station and less than two third (60.9\%) of them agreed that more training of staff was required, while $26.3 \%$ disagreed. Table (4) shows the nursing staff perception of exam atmosphere, $47.4 \%$ agreed that the environment motivated students to learn, $72.9 \%$ agreed that atmosphere was calm, while $23.3 \%$ and $27.1 \%$ agreed that exam was intimidating (frightening) and exam was very stressful respectively.

Regarding nursing staff members' perception of student performance, $84.2 \%$ agreed that students asked logical questions regarding exam, 63.9\% of them agreed that students needed more training for this type of exam, while more than one quarter $(26.3 \%)$ agreed that Students were frightened by the exam while less than two fifth $(38.3 \%)$ disagreed.

In relation to advantages of OSCE as expressed by nursing staff members, more than four fifth (88.0\%) of nursing staff members agreed that no bias in time and questions by examiners during OSCE exam and more than half $(54.9 \%)$ agreed that OSCE exam improves clinical skills \& knowledge of students. Regarding to disadvantages of OSCE as expressed by nursing staff members, most (89.5\%) of nursing staff members agreed that preparation of stations requires more resources and continuous process and $42.1 \%$ agreed that no direct interaction with examiners. The mean results showed that perception of the exam was Positive, perception of organization was also positive and perception of the atmosphere was Positive, Perception advantages as well as perception of disadvantages was Positive. Also the present study illustrated that total perception of nursing staff members regarding OSCE exam was positive (90.1\%).

The finding of the present study found that nursing staff members' perception for overall OSCE attributes was positively correlated and most of them representing moderate correlation with other factors. Noticeably that, all other factors ranged between weak and moderate correlation. Also the results of the present study donated that there is moderate correlation and significant between nursing staff members perception of students performance and their age, $r=0.196$ and $p=0.024$. Furthermore the present study reported that there are significant differences between disadvantages of OSCE as expressed by nursing staff and their occupation $\mathrm{p}=0.003$

\section{Discussion}

OSCE is gradually being recognized and accepted by nursing faculties all over the world. Dissatisfaction from previous method of clinical assessment by both nursing staff members and students lead to a search for a more appropriate method and create the OSCE. Regarding to nursing staffs' perception of OSCE question/ station the findings of the present study revealed that there was three quarters of nursing staff members agreed OSCE scores (marks) provided true measure of essential clinical skills needed by student in different disciplines. This result in agreement with (Fatah and Ali; 2012) who mentioned that $83.4 \%$ of teacher agreed OSCE scores (marks) provided true measure of essential clinical skills needed by students in different disciplines.

The results of the present study indicated that three quarters of nursing staff members agreed that OSCE Exam was fair. This result in agreement with (Idris et al; 2014) who mentioned that Eighty percent of examiners and agreed that the OSCE is fair compared with traditional clinical exam. Also this result in agreement with (Hatamleh and Abu Sabeeb; 2014) who reported that the majority of the faculty members (70\%) felt that they could stay focused while observing the same case repeatedly.

Also the present study donated that around one half of nursing staff members agreed that wide knowledge area was covered. This result convenience with (Fatah and Ali; 2012) who found one half of teachers agreed that wide knowledge area was covered. This result is disagreement with (Idris et al; 2014) Who reported that among examiners, $75 \%$ felt the OSCE covered a wide range of skills compared with TCE (traditional clinical exam),

The majority of studied sample provided positive perception about the organization of OSCE in the form of OSCE exam was well organized, sequence of stations was logical and appropriate, instructions for moving about stations were clear, Staff directed students to stations smoothly and efficiently, and staff was helpful. These findings also are consistent with (Fatah and Ali; 2012) study results. More than half of studied sample agreed that needed more time at stations and more training of staff is required. This could be due to the training workshops staff had before preparation of the OSCE. These concerns are in the line was highlighted by (Abraham et. al, 2009) who reported in a quantitative study that more than $50 \%$ of the participants felt that time was a concern during the exam. This finding is not in the line was highlighted by (Fatah and Ali; 2012) who mentioned that more than three quarters of teachers agreed that more time was needed at each station and more training of staff is required.

In relation to nursing staff perception regarding exam atmosphere one fifth of studied sample agreed that exam was intimidating (frightening) and exam was very stressful. These findings also are consistent with (Idris et al; 2014) study result in which $30 \%$ of examiners agreed that OSCE is more stressful compared to the 
old method traditional clinical exam. Also this results congruent with (Fatah and Ali; 2012) study results in which $25 \%$ of teachers agreed that exam was intimidating (frightening) and exam was very stressful. The present study revealed that less than one half of studied sample agreed that the atmosphere motivated students to learn. This finding is disagreement with (Fatah and Ali; 2012) who concluded that majority of teachers 83.4\% agreed that the environment motivated students to learn and get good results; this could be due to wide range of cases covered in the exam.

Concerning to nursing staff perception regarding to student performance, the present study revealed that less than three quarters of studied sample agreed that the students were well prepared for the OSCE. This finding is not in line with Fatah and (Ali; 2012) who concluded that 33.3\% did not think that students were well prepared for this type of exam. Also the present study indicated that less than two thirds of studied sample agreed that students needed more training for this type of examination. In contrast with the present study finding (Fatah and Ali; 2012) demonstrated that $100 \%$ of teachers thought that students needed more training for this type of exam, this could be due to the fact that in previous years students have not been exposed to this type of exam, exposure was minimal and not enough.

In spite of advantages of OSCE as expressed by nursing staff the present study found that more than half of nursing staff members agreed that OCSE improves clinical skills and knowledge of students. This result is supported by (Idris et al; 2014) who mentioned that Forty five percent of examiners felt that the OCSE improves clinical skills and knowledge of students. Furthermore, our study noticed more than two thirds of studied sample reported that OCSE is highly accepted by students and faculty. These findings also are consistent with (Idris et al; 2014) study result in which Sixty percent of examiners mentioned that the OCSE is highly accepted by students and faculty.

Also more than half of studied sample reported that stress and anxiety may be reduced compared to traditional clinical examination. In same line (Idris et al; 2014), who concluded that $65 \%$ of students reported that stress and anxiety may be reduced compared to traditional clinical examination. In contrast with this finding (Hatamleh and Abu Sabeeb; 2014) who found that students' stress level impacted their performance on OSCE $50 \%(\mathrm{n}=10)$ agreed, and only $10 \%$ disagreed,

Regarding to disadvantages of OSCE as expressed by nursing staff members the present study revealed that more than three quarters of nursing staff members agreed that only specific questions are to be asked as in checklists or model answers and $89.5 \%$ of studied sample reported that preparation of stations requires more resources and continuous process. In same line (Hatamleh and Abu Sabeeb; 2014), who concluded that among examiners, the disadvantages were; in $65 \%$ only specific questions are to be asked as in checklist or model answer and 95\% preparation of OSCE stations requires more resources (time, effort, examiners and expenses). The present study has demonstrated that less than two thirds of studied sample mentioned that a pattern of questions may be formed and students will study only concerned topics. This finding is disagreement with (Hatamleh and Abu Sabeeb; 2014), who found that among examiners in 90\% a pattern of questions may be formed and students will study only concerned topics.

Furthermore, our study noticed that the mean results were positive for all the domains in the questionnaire and total perception of nursing staff members regarding OSCE exam was positive (90.1\%).This finding is quite expected and is congruence with (Fatah and Ali; 2012) who concluded that the mean results showed that perception of the exam was good, perception of organization was also good and perception of the atmosphere was good. Perception of real patients and simulator patients as well as perception of the students was good.

\section{Conclusion}

Overall, the mean results were positive for all the domains in the questionnaire and total perception of nursing staff members regarding OSCE exam was very positively. It was concluded that this type of exam highlighted student's weaknesses, it was a fair exam and provided real measure of clinical skill competency, OCSE improves clinical skills and knowledge of students. Exam was well organized, instructions were clear, staff directed students to stations smoothly and efficiently, and staff was helpful. Study also concluded that more staff was needed during the exam. Also the majority of nursing staff members reported that preparation of stations requires more resources and continuous process

\section{Recommendations}

Students should also be trained for this type of exam; the best way is to start examining them using this strategy (OSCE) earlier and more preparatory activities during the semester More staff needed is for this type of exams and more training should be done to staff through journal club. 


\section{References}

[1]. Abraham R, Raghavendra R, Surekha K, and Asha K. A trial of the objective structured practical examination in physiology at Melaka Manipal Medical College, India. Adv Physiol Educ, 33(1), 2009, 21-23.

[2]. Ahmed, C, Ahmed, N \& Abu Baker, R , (2009). Assessing nursing clincal skills performance using objective structured clincal examination (OSCE) for open distance learning students in open university Malaysia international conference on information ' Kuala Lumpur , 12 - 13 August

[3]. Baid, H., 2011. The Objective Structured Clinical Examination within intensive care nursing education. Nursing in critical care, British Association of critical care nurses, 16: 99-105.

[4]. Bartfay, W. J., Rombough, R., Howse, E., \& LeBlanc, R. 2004. The OSCE approach in nursing education: Objective structured clinical examinations can be effective vehicles for nursing education and practice by promoting the mastery of clinical skills and decision-making in controlled and safe learning environments. The Canadian Nurse 100(3), 18-25.

[5]. Casey,P.M., AR. Goepfert and Espey, 2009. The Objective Structured Clinical Exami nation. Obstetric Gynecol, $200: 25-34$.

[6]. Eswi A, Badawy A, and Shaliabe H, (2013): OSCE in Maternity and Community Health Nursing: Saudi Nursing Student's Perspective, American Journal of Research Communication Vol 1(3))

[7]. Fatah S and Ali A. Teacher's perception of the first implemented OSCE mock as a reference for perfection in the final clinical exam for medical students Al Neelain Medical Journal NMJ vol (4) March 2012.

[8]. Hatamleh W and Abu Sabeeb Z. Perception of Nursing Faculty Members on the Use of Objective Structured Clinical Examinations (OSCE) To Evaluate Competencies. OSR Journal of Nursing and Health Science (IOSR-JNHS) Volume 3 , Issue 6 Ver. IV (Nov.-Dec. 2014), PP 21-26 www.iosrjournals.org

[9]. Hosseini SA, fatehi N, Eslamian J and Zamani M (2011): Reviewing the nursing students' views toward OSCE test Iran J Nurs Midwifery Res. 2011 Autumn; 16(4): 318-320)

[10]. Idris SA, Hamza A, Hafiz M and Eltayeb M (2014) Teachers' and students' perceptions in surgical OSCE exam: Open Science Journal of Education; 2(1): 15-19)

[11]. Liddle C (2014) The objective structured clinical examination Nursing ,Nursing Times Vol 110 Online issue / www.nursingtimes.net)

[12]. Mahmoud G., Mostafa. M., (2011): The Egyptian Nursing Student's Perceptive view about an Objective Structured Clinical Examination (OSCE). Journal of American Science, 7(4):730-738

[13]. Mater E, Ahmed E, ElSayed A,EI Shaikh M and Farag M(2014) The Impact of the Objective Structured Clinical Examination Approach for Clinical Evaluation Skills on the Student's Performance in Nursing College World Journal of Medical Sciences 11 (4): 609-613, 2014

[14]. Miller, G. 1990. The assessment o clinical skills / competence / performance. Academic Medicine 65 (Suppl.9), S63-S67.

[15]. Mitchell ML $\mathbf{1}^{\mathbf{1}}$, Henderson A, Groves M, Dalton M, Nulty D.( 2009)The Objective Structured Clinical Examination (OSCE): Optimising its value in the undergraduate nursing curriculum. Nurse Educ Today.May;29(4):398-404.

[16]. Nady F, Zahran K, Youness E, and Hassn H; (2014). Women's knowledge and perception about benefits of folic acid intake before and during pregnancy according to health belief model in Beni-Suif city. Assiut Scientific Nursing Journal, vol (2), No (3), June 2014

[17]. Raheel, H. and N. Naeem, (2013). Assessing the Objective Structured Clinical Examination: Saudi family medicine undergraduate medical students 'perceptions of the tool. JPMA, 36: 281-1283

[18]. Saegh R, Scherpbier A, Alhibaly H, Hmood A and Almkhtar M(2015) Perception of OSCE Examination in Iraqi Undergraduate Medical Students Karbala J. Med. Vol.8, No.1.

[19]. Selim, A., F. Ramadan, M. El Geneidy and M. Gaafer (2012). Using Objective Structured Clinical examination (OSCE) in undergraduate Psychiatric nursing education: is it reliable and valid. Nursing education today Journal, 32: 283-288.

[20]. Walsh, M., P.H. Bailey and I. Koren, (2009). Objective structured clinical evaluation of clinical competence: an integrative review. Journal of Advanced Nursing,65: 1584-1595.

[21]. Zayyan M (2011): Objective Structured Clinical Examination: The Assessment of Choice, Oman Med J. Jul; 26(4): 219-222.) 